\title{
Implementation of a geothermal heat pump system in a solar passive house
}

\author{
Gheorghe Ilisei ${ }^{1}$, Tiberiu Catalina ${ }^{1,2^{*}}$, Marian Alexandru ${ }^{1}$, and Robert Gavriliuc ${ }^{1}$ \\ ${ }^{1}$ Technical University of Civil Engineering, Faculty of Building Services, Bucharest, Romania \\ ${ }^{2}$ Solar Decathlon Association, Bucharest, Romania
}

\begin{abstract}
Underground energy sources are becoming increasingly popular and now geothermal heat pumps are frequently used to heat/cool different types of buildings, including for solar passive houses. This article aims at giving a contribution in the development of the thermal modelling of borehole heat storage systems, investigating the possibility of a GSHP (ground source heat pump) implementation with vertical boreholes in a solar passive house. A case study analysing a residential solar passive house is presented as a suitable modelling tool for the estimation of the thermal behaviour of GSHP systems by combining the outcome from different modelling programs. The software DesignBuilder, Earth Energy Designer and a sizing method for borehole's length are used for producing the numerical results. The results highlight that the length of the borehole, a major index in estimating the system's cost, is directly influenced by fundamental variables like thermal conductivity of grout or soil. Additionally, correlations between these parameters and the coefficient of performance of GSHP were made. Furthermore, the length of borehole is very important as it is responsible for almost half of the total installation cost and triggered a difference in electricity consumption of the GSHP up to $14 \%$.
\end{abstract}

\section{Introduction}

Considering the instability of the price of fossil fuels and the need for a strong reduction in $\mathrm{CO}_{2}$ emissions, in the context of increased global awareness and in the context of the European Union taking strong action by 2020 to mitigate the effects of climate change, renewable energies (alongside geothermal resources) will expand their use and applications. However, there are many countries, some even in Europe, where these types of equipment are often not considered in the design of a building due to lack of studies, information, available examples and insufficient cost analyses.

Energy use in buildings represents a major share of the overall energy used in developed countries. The reduction of the energy demand and the efficient energy use are often seen as feasible ways for a more sustainable energy use in the built environment. Ground source heat pumps are efficient systems to supply heating and cooling energy to buildings, but their design is critical for their performance. Furthermore, their performance depends on the cooling and heating demand and on the environmental conditions (geometric and physical properties of its components and the thermohydrogeological properties of the surrounding soil) [1, 2].

\section{Nomenclature}

\begin{tabular}{|l|l|}
\hline GSHP & Ground Source Heat Pump \\
\hline HDPE & High Density Polyethylene \\
\hline
\end{tabular}

\begin{tabular}{|c|c|}
\hline EED & Earth Energy Designer \\
\hline BHE & Borehole Heat Exchanger \\
\hline ASHRAE & $\begin{array}{l}\text { The American Society of Heating, } \\
\text { Refrigerating and Air Conditioning }\end{array}$ \\
\hline HVAC & Heat Ventilation and Air Conditioning \\
\hline LTGE & Low Temperature Geothermal Energy \\
\hline $\mathbf{k}_{\mathbf{p}}$ & Thermal conductivity of the HDPE pipes \\
\hline d & Drilling diameter \\
\hline kg & $\begin{array}{l}\text { Thermal conductivity of the well's filling } \\
\text { material (grout) }\end{array}$ \\
\hline ks & Thermal conductivity of the ground/soil \\
\hline $\mathbf{T}_{\mathrm{g}}$ & Initial temperature of the ground \\
\hline $\mathbf{R}_{\mathbf{b}}$ & Thermal resistance of the wells/boreholes \\
\hline
\end{tabular}

A passive solar house is a building designed to assure that all of its elements, as windows, walls, roof and floors are made to collect, store, reflect, and distribute solar energy in the form of heat in the winter and to reject solar heat in the summer [3].

The key to design a passive solar building is to use as much as possible the local climate and also to perform an accurate site analysis. Elements to be considered include window placement, size, glazing type, thermal insulation, thermal mass, and shading [4]. Passive solar design techniques can be applied most easily to new

\footnotetext{
* Corresponding author: ilisei.g@gmail.com
} 
buildings, but existing buildings can be adapted or "retrofitted".

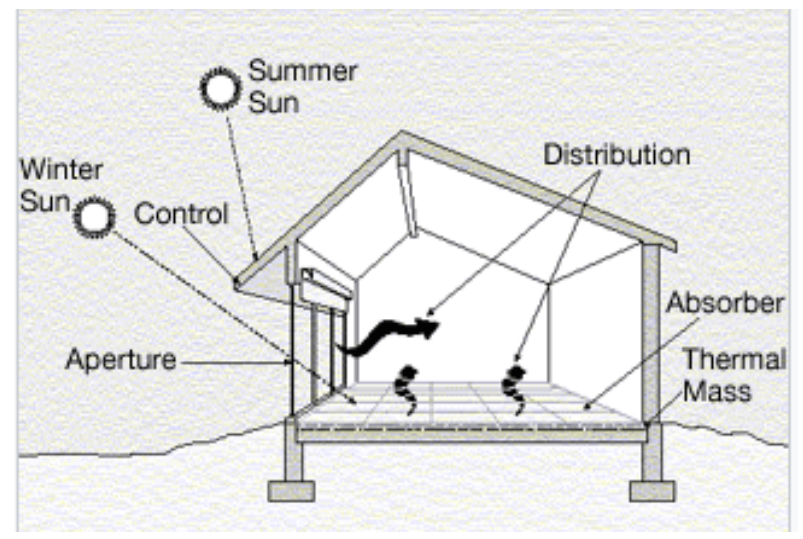

Fig. 1. Elements of passive solar design shown on a residential house.

The purpose of this study is to highlight the benefits of a ground source heat pump on BHE (borehole heat exchangers) for a solar passive house. The particularity of a GSHP implementation in a passive solar house compared to any other building is reflected by the low energy consumption both in heating and cooling demand compared with other buildings with a regular conformation. To do that some correlations were made between two different modeling programs and another sizing tool (for the length of geothermal loop) by combining the data provided from them in order to obtain a tool that would be used for easy modeling of such a system (a geothermal heat pump served by vertical geothermal BHE).

In the process of persuading a beneficiary to adopt a geothermal heat pump for a residential house, it is imperative to present alongside with the advantages of the system, the financial competitiveness of it with other HVAC options. Consequently, one crucial condition to be respected by the system to be considered a viable solution is to avoid being oversized.

Considering that many implemented geothermal systems for residential houses do not work at full capacity, this method of combining several modeling tools aims at a correct dimensioning by combining the results of the programs and adapting the BHE length according to the geotechnical parameters of the earth and thus, optimizing the system.

The simulations were realized using different types of heat pumps, different types of soil and different types of vertical drilling.

Among the studies conducted in this direction, it is important to mention the doctoral work of Valentin Trillat, which consists of a study of a combined solar system simultaneously integrating solar thermal energy and low temperature geothermal energy. The system was installed on a single house in France and the results were collected during its first 18 months of operation [5].

Additionally, there are many studies in Italy and Sweden that analyzed the efficiency of closed loop geothermal heat pumps. Among the most important ones, the study of the Department of Engineering of the University of Perugia, "Feasibility study and numerical simulation of a ground source heat pump plant, applied to a residential building" [6], along with some studies made in Sweden by Royal Institute of Technology, like "The application of the parametric analysis for improved energy design of a ground source heat pump for residential buildings" need to be highlighted [7].

\section{Objectives}

The aim of this article is to study the possibility of implementing a geothermal heat pump with vertical drilling (a closed-loop system) to meet the heating / cooling demand of a passive house and to highlight some benefits of this equipment even for a small building.

The objective is to see if such a system can ensure the heating and cooling demand of the building described and to minimize the number of boreholes and their depth to make the implementation of such a system a viable solution for cooling and heating a house.

To do this, several simulations were made for the analysed building with the software mentioned below and the results of the simulations were used to make a connection between them, analyze them and show the reliability of implementation of such a system also for small buildings. Given that the performance of a geothermal heat pump depends on both thermal and hydrogeological properties of the soil and architecture (number, position, diameter, depth, etc.) of the boreholes, several simulations were realized at the same time using advanced modelling tools (Design Builder and EED). The simulations were made for a passive house with a given architecture.

On one hand, the Design Builder software takes into consideration throughout the simulations the entire building to model the HVAC system that is used for this building and to provide data such as the heating/cooling demand. On the other hand, the EED software only analyses the vertical drilling system that is used for the design and dimensioning of vertical heat exchangers. To size the length of the vertical borehole exchangers an Excel tool/ spreadsheet (using ASHRAE method) has been designed and used for modelling of thermal exchanges between soil and heat transfer fluid of vertical buried heat exchangers.

\section{Study case building}

The case study was carried out on an energy-efficient house EFdeN House, a single-family dwelling that was planned and built in Bucharest for academic purposes.

The designed building is built on two levels - ground floor and first level, with residential pavilion and exhibition pavilion, consisting of:

a) Ground floor: slope, ramp, terrace, windfang $4.3 \mathrm{~m}^{2}$, entrance hall $4.8 \mathrm{~m}^{2}$, bathroom group $2.5 \mathrm{~m}^{2}$, technical room $3.1 \mathrm{~m}^{2}$ for electrical installations, kitchen $20.75 \mathrm{~m}^{2}$, living room $25.5 \mathrm{~m}^{2}$, greenhouse of $9.95 \mathrm{~m}^{2}$;

b) $1^{\text {st }}$ Floor: hall $8.6 \mathrm{~m}^{2}$, master bedroom $18 \mathrm{~m}^{2}$, bedroom $13.3 \mathrm{~m}^{2}$, bathroom $3.1 \mathrm{~m}^{2}$, lock/ rest room $2.65 \mathrm{~m}^{2}$, technical room for HVAC system $7.4 \mathrm{~m}^{2}$, greenhouse. 
Important building data:

- Height regime: ground floor + first floor

- Building destination: residential building

- Built area: $170 \mathrm{~m}^{2}$

- Useful area: $133 \mathrm{~m}^{2}$

- Height: $2.5 \mathrm{~m}$

- Number of occupants: 3

- Location: City of Bucharest.

- Cooling load(summer): 3.5 [kW] (DesignBuilder)

- Heating load (winter): 4.2 [kW] (DesignBuilder)

A distinctive feature of the construction is the integration of the greenhouse with the bioclimatic role. It will be partially integrated into the construction. The heart of the house is this greenhouse, which is also an oasis, a part of the house with multiple functions from thermal advantages on energy consumption to gardening. From a decorative function to the possibility of gardening, from a place of relaxation to a place of social interaction, the greenhouse offers a range of uses adaptable to the needs of the inhabitants.

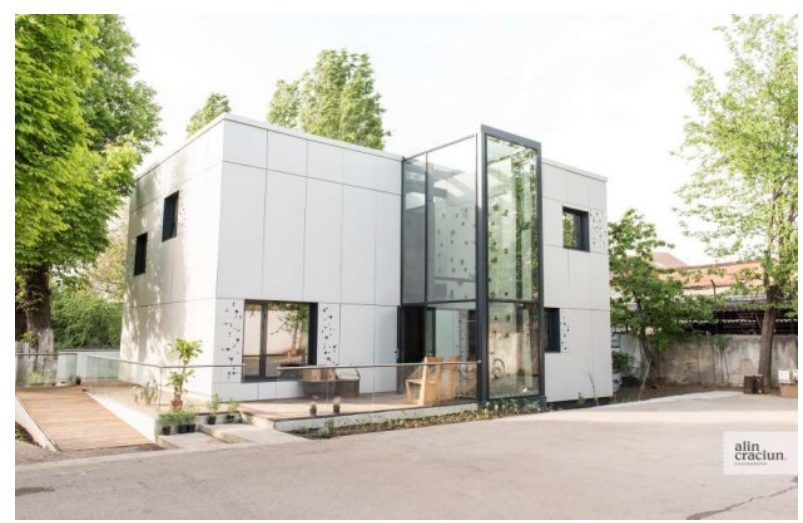

Fig. 2. Solar House EFdeN - outside photo.

The process of creating the solar architecture is determined by certain bioclimatic strategies essential to the project.

The first step in this direction is the simple shape of the house: the volume has been designed to reduce heat losses. In this regard, an important point in the project strategy is the greenhouse. In winter, it serves as a thermal buffer because of its southern orientation. Glazed glass surfaces facilitate solar gain in winter, when the incidence of sunlight is low. Additionally, during winter, the greenhouse will provide preheated air which will be used in the home's heating system.

By thinking of sustainable solutions over time to create a minimalist architecture, the house configuration is carefully designed for advantageous lighting, for efficient thermal protection (adapted to extreme climatic conditions in Romania) and for low energy consumption.

The project contains contrasting materials, plants and mineral elements, recycled (wood, OSB) and recyclable (metal structure, facade panels in ceramic elements).

The objective of the energy analysis of the house as well as the systems implemented in the EFdeN house is to obtain an optimal interior comfort with low energy consumption. To do this, several energy-efficient active solutions are needed, as well as the use of passive solutions. The house was built for Romanian climate zone II, and the design calculations were considered as multiple destinations for this (residential building and exhibition pavilion). To maintain the indoor air parameters in the comfort zone as well as in domestic hot water, a high performance water-to-water geothermal heat pump $(\mathrm{COP}=4)$, with a heating capacity of $6.5 \mathrm{~kW}$ and a cooling capacity of $5.1 \mathrm{~kW}$ is proposed. Due to the high coefficient of performance, the heat pump will consume only $1 \mathrm{~kW}$ of electrical energy to produce $4 \mathrm{~kW}$ of heat.

\section{Methodology / Simulations}

For the simulations, DesignBuilder, an EnergyPlusbased software tool used for the measurement and control of energy, carbon, lighting and comfort [8] has been used. DesignBuilder combines fast modeling of three-dimensional buildings with dynamic energy simulations thanks to its unique ease of use. For this study, the building architecture was introduced in DesignBuilder as a 3D Model (see Figure 3).

To simulate the behavior of a Geothermal Source Heat Pump installed in the EFdeN house, it was first introduced the building architecture and then it was modeled the HVAC system [9].

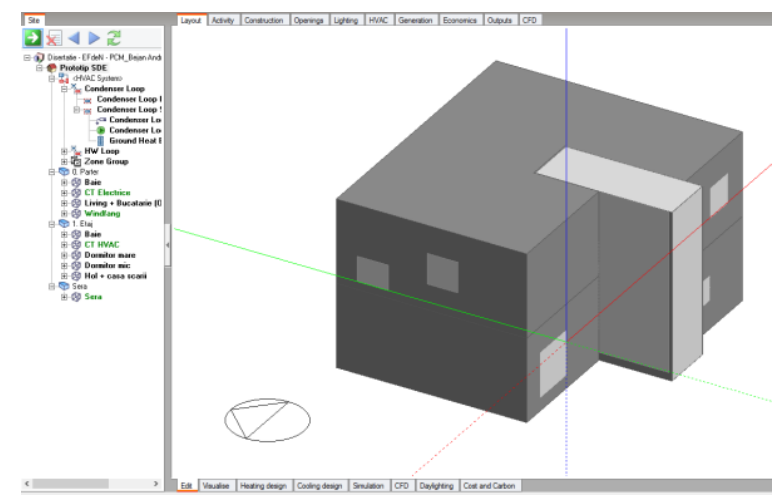

Fig. 3. Solar House EFdeN - 3D Model in Design Builder.

To introduce the architecture of the house a few steps have been followed.

\section{Thermal zoning}

The energy modeling of the building begins with the introduction of its thermal zones. A thermal zone denotes a room or several rooms having the same thermo-technical characteristics, orientation, installations, etc. In this case, each part is a thermal zone.

2. Introduction of the thermo-technical characteristics of the inertial elements of the envelope.

After the thermal zoning of the building, the envelope proprieties were introduced: external walls, terrace, intermediate plans, ground floor, windows, etc.

3. Presentation of activity types and interior comfort parameters. Scenarios

After the introduction of the elements of the envelope depending of the type of room, the level of occupation, the scenarios of occupation, the type of activity, the water consumption, the indoor temperature during 
summer, the indoor temperature during winter and the indoor heat gains have been defined.

After introducing into the software the architecture of the building analyzed with all the other input data (the layers of each wall, the occupancy scenarios, heat gains, climate data, etc.), it was defined the HVAC system.

In the Design Builder software, geothermal heat pump systems consist essentially of two loops (only heating or cooling for the house) or three loops (both heating and cooling for the analyzed house). In this case, these 3 loops are necessary to represent the heat pump system:

- HW loop (for heating applications) - Hot water loop (water-to-water heat pump heating)

- CHW loop (for cooling applications) - Chilled water loop (water-to-water heat pump cooling)

- Condenser loop - Ground heat exchanger loop (exchange of heat with the ground via the surface of vertical borehole exchangers (heat is transported to the heat carrier fluid)).

The maximum demand (peak load) of the EFdeN house is $4.2 \mathrm{~kW}$ for heating and $3.5 \mathrm{~kW}$ for cooling. The simulations were realized for Bucharest, Romania.

The smallest heat pump was selected in Design Builder and it consisted of a maximum heating capacity of $6.5 \mathrm{~kW}$ and a cooling power of $5.1 \mathrm{~kW}$. The design of the system is composed of multiple borehole heat exchangers, a heat pump and the heated/cooled floor (see Figure 4).

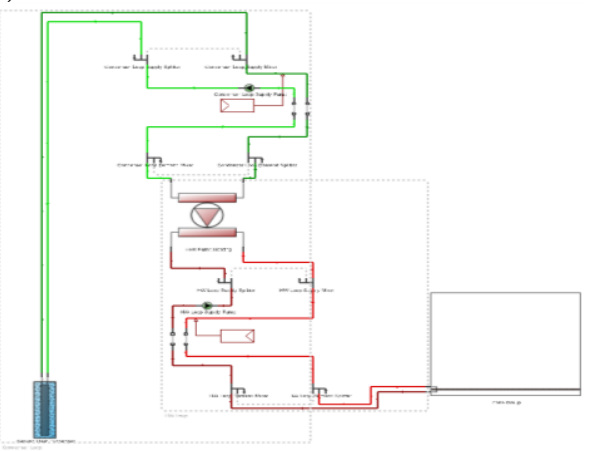

Fig. 4. GSHP model with vertical boreholes and heated floor.

Design Builder is limited in terms of proposing the optimum number of boreholes or their length. These data must be introduced by the user randomly. To better approximate and correctly choose the right number of boreholes a second simulation program was used.

Earth Energy Designer is a software used for the design of vertical boreholes as heat exchangers for a heat pump [10]. It is ease of use, short learning curve, fast calculation times and inherent databases make EED a useful tool in everyday engineering work for the design of the geothermal heat pump system. EED is based on parameter studies with a numerical simulation model resulting in analytical heat flow solutions with several combinations for the drilling model and geometry ( $\mathrm{g}$ functions). EED has databases that provide the soil parameters (thermal conductivity and specific heat - see Table 1) as well as the properties of piping materials and heat transfer fluids. The average monthly heating and cooling demands along with the peak load for heating/cooling of the analyzed building are the input data. In our case, these values were obtained previously from a Design Builder simulation. The thermal resistance of the borehole is also calculated in the program, using borehole geometry (see Figure 5), joint material, pipe material and geometry. The 10-year simulation period was chosen to see how the temperature in the soil will vary.

Table 1. Soil and GSHP coolant properties.

\begin{tabular}{|c|c|}
\hline \multicolumn{2}{|l|}{ Soil properties } \\
\hline Characteristics & Value \\
\hline Thermal conductivity & $2.2 \mathrm{~W} / \mathrm{mK}$ \\
\hline Volumetric heat capacity & $2.4 \mathrm{MJ} / \mathrm{m}^{3} \mathrm{~K}$ \\
\hline Ground surface temperature & $10.60^{\circ} \mathrm{C}$ \\
\hline Thermal conductivity of the grout & $1.8 \mathrm{~W} / \mathrm{m}^{2}$ \\
\hline \multicolumn{2}{|c|}{ Coolant properties } \\
\hline Thermal conductivity & $0.372 \mathrm{~W} / \mathrm{mK}$ \\
\hline Specific heat capacity & $4030 \mathrm{~J} / \mathrm{kgK}$ \\
\hline Density & $961 \mathrm{~kg} / \mathrm{m}^{3}$ \\
\hline Freezing point & $-25^{\circ} \mathrm{C}$ \\
\hline
\end{tabular}

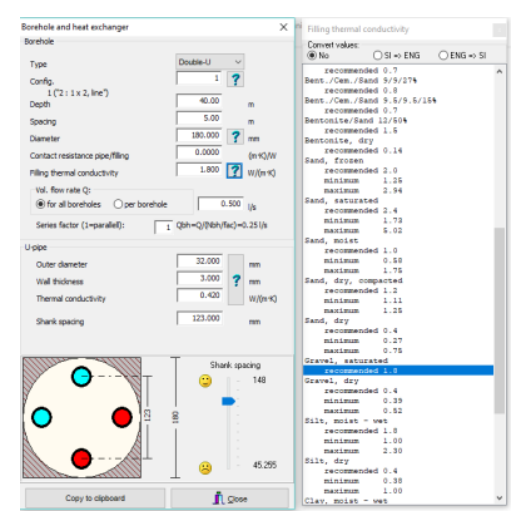

Fig. 5. EED software vertical boreholes and filling material properties.

With the data obtained from EED, the next step was to start to simulate once again the house with Design Builder. The same data for the soil, boreholes geometry, coolant and filling material were used in both of the software.

\section{Results}

After assessing the needed length of the borehole heat exchanger for heating/cooling the Efden house and for its location and after the introduction of the detailed HVAC system with the help of DesignBuilder, the next goal was to make a comparison by analysing different types of soil, different HDPE pipes, different filling materials, different length and number of boreholes in order to see their influence on electricity consumption of the GSHP for heating. These results are obtained by doing various simulations of the house in DesignBuilder.

Additionally, using the software EED and an Excel spreadsheet calculation sheet, the next step was to start 
to vary the types of soil, filling material, the GSHP, the location and others to see which factors have the higher influence on the borehole's length. This is very important for the feasibility of such a system as the BHE's length is essential in order to assure that the system is not oversized so it can be considered a viable solution.

Firstly, the influence of the thermal conductivity of the filling material, of the $U$ pipes and of the soil have a strong impact on the electricity consumption during heating/cooling season and also on the COP of the system is analysed, as can be seen in table 2 .

Table 2. Conductivity values for soil, filling material, pipes and simulation results for 3 cases (A,B and C).

\begin{tabular}{|c|c|c|c|}
\hline Conductivity (W/mK) & Case A & Case B & Case $\mathrm{C}$ \\
\hline U type pipes & 0.39 & 0.42 & 0.42 \\
\hline Filling material & 0.7 & 1.8 & 2.5 \\
\hline Soil & 0.7 & 2.2 & 2.6 \\
\hline \multicolumn{4}{|c|}{ Results - annual values } \\
\hline Heating energy $(\mathrm{kWh})$ & 2611 & 2611 & 2611 \\
\hline Electricity consumption $(\mathrm{kWh})$ & 773.9 & 679.5 & 666.8 \\
\hline Coefficient of Performance (-) & 3.37 & 3.84 & 3.91 \\
\hline
\end{tabular}

Thus, it can be observed that the consumption for heating the building is smaller if the thermal conductivities of the soil and of the filling material have higher values. To be more explicit it can be seen that electricity consumption drops with $12.19 \%$ for case B and with $13.84 \%$ for system $C$ when materials with better thermal properties are used. Moreover, this table highlights the connection between the COP of the pump and the thermal conductivity of the soil and of the filling material.

Secondly, there are presented the influence of the input parameters mentioned above on the borehole's length. The main parameters analysed are the thermal conductivity of the well filling material (the grout) $\left(\mathrm{k}_{\mathrm{g}}\right)$, the thermal conductivity of the ground $\left(\mathrm{k}_{\mathrm{s}}\right)$ and the initial temperature of the ground $(\mathrm{Tg})$ because they have a greater influence than the others.

The greatest influence on the length of the BHE is given by $\mathrm{kg}_{\mathrm{g}}$. Thus, if the thermal conductivities of the soil and of the filling material and the initial soil temperature are all underestimated by $10 \%$ each, the error on the length of the buried exchangers can reach a value of approximately $30 \%$.

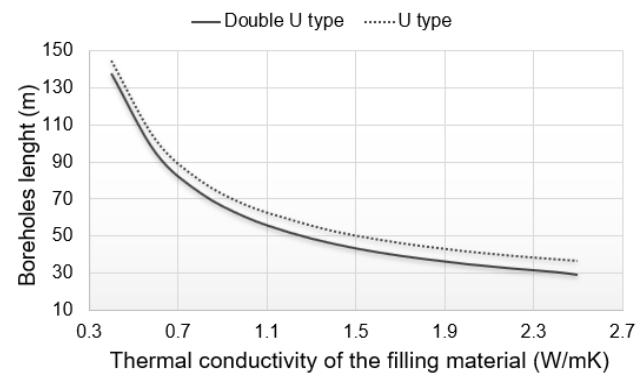

Fig. 6. Influence of the thermal conductivity of the filling material on the BHE length.

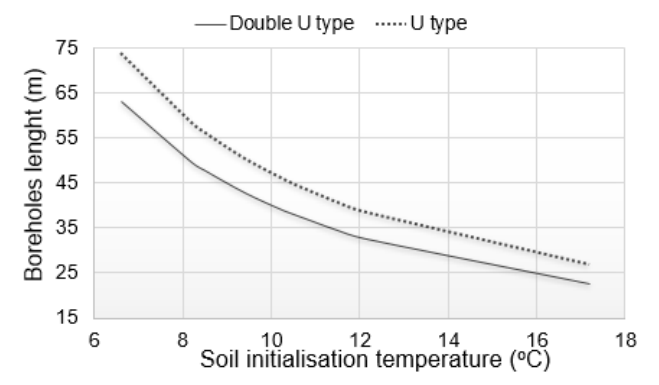

Fig. 7. Influence of the initial mean ground temperature on the BHE length.

In what concerns the soil temperature, this can have a huge impact on the borehole length sizing. It is recommended to introduce the correct information on this parameter as $1^{\circ} \mathrm{C}$ can decrease/increase the length by $15 \%$. Using the double $U$ type piping is preferable as for the same soil temperature it was observed a decrease of the borehole length of $12 \%$.

Finally, the purpose was to connect the most two important parameters when designing a GSHP served by BHE: COP of the pump and the length of the BHE. Additionally, a connection between the electricity consumption of the compressor and the length of the borehole was made (see Figure 8). It can be concluded that doubling the length of the boreholes from $50 \mathrm{~m}$ to $100 \mathrm{~m}$ decreased the energy consumption from $150 \mathrm{kWh}$ to $125 \mathrm{kWh}(-17 \%)$. Thus, it is clearly that correct sizing of the system is important in order to avoid an oversizing of the length of the BHE. Otherwise, the price of the system will increase considerably making the project not feasible. To be more specific, some sources state that the length of the Borehole Heat Exchanger it is responsible for almost half of the total installation cost of the GSHP $[11,12]$.

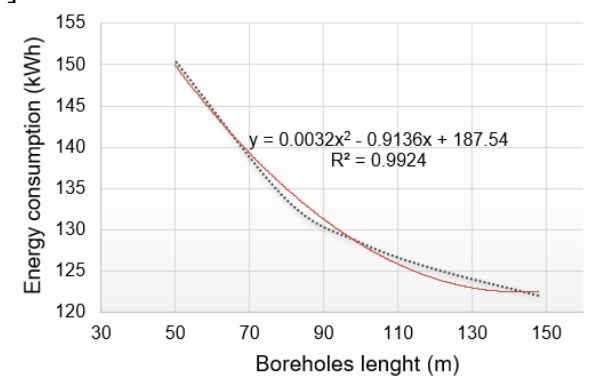

Fig. 8. Influence of the borehole's length on the heating consumption.

\section{Conclusions}

The purpose of this study was to make a link between two simulation programs and to combine the data provided from them in order to obtain the best analysis of a GSHP implementation on BHE. Both software, DesignBuilder and EED, give important information for the design of vertical borehole heat exchangers.

On the one hand, Design Builder was useful and provided the following information:

- How the length of boreholes influences the coefficient of performance; 
- How the thermal conductivity of filling material, of soil and of pipe influences electricity consumption of the heat pump.

The heating/cooling demand and the maximum load for heating/cooling were used in EED software to provide the optimum number of boreholes and their length. Additionally, the data were used in dimensioning the length of the BHE with the Excel file (using ASHRAE method).

On the other hand, EED provided the following information:

- How heating requirements and maximum loads influence the boreholes length;

- How the conductivity of soil, of filling material and of soil temperature influence the boreholes sizing;

Finally, the ASHRAE method, which is used to highlight the reliability of the results, gives the necessary drill length to meet the needs and the peak loads of the EFdeN house.

It also highlights the effects that the conductivity of soil and of filling material, the soil temperature, the COP of the GSHP and the rate flow of the heat carrier fluid have over the length of borehole.

It is recalled once again that the length of the borehole is really important for the feasibility of such a project (building served by a geothermal heat pump on vertical borehole heat exchangers) because the cost of drilling is high and it greatly influences the cost of implementing such a project. As it was stated before, the cost for the implementation of the Borehole Heat Exchanger can be up to half of the total installation cost of the GSHP. Thus, if the length of the boreholes is oversized and the project seems expensive to be implemented, the owner/investor/constructor can easily move towards another more economically viable solution.

The results of the three tools show that the results have the same direction, and the drilling length of the $\mathrm{BHE}$ is really influenced by the parameters described above in the results section (thermal conductivity of soil, of filling material, etc.), but the differences (the percentages in which some parameters modify the length of the borehole) are not necessarily the same. (Even in the case when the same input parameters were utilised for different analysis tools (EED, DesigBuilder, Excel spreadsheet using ASHRAE method))

For example, the influence of the conductivity of the filling material is not so pronounced / large in the results obtained with EED and DesignBuilder as it is in the calculations done with the Excel spreadsheet. This is understandable since the Excel spreadsheet is only a calculation tool for assessing approximately the length of the BHE.

To sum up, it is advisable to combine the results of simulations with several programs, because some software may have limitations.

For example, Design Builder does not directly indicate the influence of changing the soil type or the heat pump on the lengths of drilling (but on the electricity consumption). Thus, the use of other programs helped to see the influence of soil type on the drill length and thus a correlation between the results obtained with different software can be made.

In addition, using the EED software or/and the ASHRAE method, offered the ability to correctly insert a drill length into the Design Builder simulation, which could have been otherwise oversized.

The paper has been elaborated within the research activities of the European Project "Most easy, efficient and low cost geothermal systems for retrofitting civil and historical buildings", acronym GEO4CIVHIC - grant agreement No. 792355, covering Task 5.4-Modelling of virtual cases study, Sub task 5.4.4 Virtual case No. 4: Residential building in Bucharest (ROMANIA).

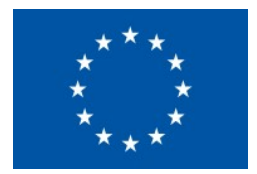

\section{References}

1. Marco Molinari, Alberto Lazzarotto, Folke Bjork The application of the parametric analysis for improved energy design of a ground source heat pump for residential buildings, Elsevier magazine, Vol. 63, 2013

2. Alessandro Casasso, Rajandrea Sethi*, Sensitivity analysis on the performance of a ground source heat pump equipped with a double U-pipe borehole heat exchanger, Torino, Italy, 2014

3. Doerr, Thomas (2012). Passive Solar Simplified (1st ed.). Retrieved October 24, 2012.

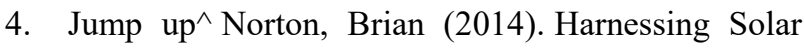
Heat. Springer. ISBN 978-94-007-7275-5.

5. Valentin Trillat, Intégration énergétique dans les bâtiments par l'utilisation combinée de l'énergie solaire et de la géothermie basse température, Universite de Savoie-Chambery, France, 2006

6. U. Desideri*, N. Sorbi, L. Arcioni, D. Leonardi, Feasibility study and numerical simulation of a ground source heat pump plant, applied to a residential building, Perguai,, Italy, 2011

7. Marco Molinari, Alberto Lazzarotto, Folke Bjork The application of the parametric analysis for improved energy design of a ground source heat pump for residential buildings, Elsevier magazine, Vol. 63, 2013

8. http://www.altensis.com/en/services/designbuildersoftware/

9. http://www.designbuilder.co.uk/helpv3.4/\#GSHPCa seStudy.htm

10. https://buildingphysics.com/eed-2

11. Michopoulos A, Kyriakis $\mathrm{N}$, The influence of $a$ vertical ground heat exchanger length on the electricity consumption of the heat pumps, Renewable Energy, 35 (2010) 1403-1407.

12. Blum P, Campillo G, Kölbel T. Techno-economic and spatial analysis of vertical ground source heat pump systems in Germany. Energy 2011. 